\title{
PENENTUAN KAPASITAS PRODUKSI UNTUK MENINGKATKAN PRODUKTIVITAS KERJA PADA IKM SEMPRONG DI KABUPATEN KARAWANG
}

\author{
Muhamad Sayuti \\ Program Studi Teknik Industri, Universitas Buana Perjuangan Karawang \\ Jl. HS. Ronggowaluyo Telukjambe Timur, Karawang 41361 \\ email: muhamad.sayuti@ubpkarawang.ac.id
}

\begin{abstract}
ABSTRAK
Industri Kecil dan Menengah (IKM) merupakan industri yang semakin berkembang di Indonesia. Industri ini merupakan salah satu yang tahan dari kerisis ekonomi, sehingga bisa menjadi alternatif usaha untuk di kembangkan. Kue semprong merupakan hasil dari industri kecil dan menengah yang di kembang di Karawang. Kue semprong merupakan makanan khas Karawang, sehingga banyak sekali orang membeli kue ini sebagai oleh-oleh khas daerah.

Produksi kue semprong sangat berpengaruh terhadap permintaan dari konsumen, tetapi selain permintaan yang mempengaruhi yaitu jumlah tenaga kerja. Penelitian ini akan meneliti bagaimana penentuan kapasitas produksi untuk menentukan jumlah pegawai yang dipekerjakan, sehingga dapat mempengaruhi kapasitas produksi.

Setelah dilakukan perhitungan dengan menggunakan waktu baku, waktu standard an waktu normal, dari masing-masing kegiatan pengelolahan bahan, pencetakan dan pengemasan. Dengan rata-rata produksi 848 perbulan, dibutuhkan tenaga kerja masing-masing kegiatan diatas yaitu membutuhkan karyawan sebanyak 25 orang dalam satu kegiatan. Jumlah karyawan tersebut untuk meningkatkan produktivitas dan meningkatkan kapasitas produksi.
\end{abstract}

Kata Kunci : Kapasitas Produksi, produktivitas, IKM Semprong 


\section{PENDAHULUAN}

Produk usaha kecil menengah semakin berkembang, seiring dengan dibentuknya Badan Ekonomi Kreatif (BEKRAF) oleh pemerintah. Badan Ekonomi Kreatif ini memberikan wadah dan gagasan untuk mengembangkan Usaha Kecil dan Menengah di Indonesia. Semakin banyak usaha baru yang muncul dan berkembang di karenakan kebijakan ini. Salah satunya adalah usaha semprong asal kabupaten Karawang ini, semakin hari semakin banyak peminatnya dan semakin luas pemasarannya.

Semprong merupakan produk unggulan dari Karawang dan menjadi salah satu produk unggulan. Semakin hari produk ini semakin di buru untuk oleh-oleh khas karawang, dan menjadi makanan favorit masyarakat sekitar. Berkembangnya pariwisata dan industri.

\section{TINJAUAN PUSTAKA}

Sebagian besar perusahaan, terutama industri kecil menengah (IKM), menghadapi permintaan musiman dan masalah produksi, yang mengarah pada munculnya periode lean dan puncak. Variasi dalam permintaan dan penawaran seperti itu biasanya di luar kendali pabrikan. Dalam praktik saat ini, pendekatan untuk masalah ini adalah merencanakan berdasarkan kapasitas produksi, kapasitas mesin atau ruang penyimpanan, untuk mengakomodasi beragam permintaan. Masalah perencanaan produksi sering ditangani melalui penggunaan model matematika atau teknik pendukung keputusan kuantitatif yang sistematis. Sebagai contoh, model optimasi linier digunakan untuk lingkungan produksi (Lim et al., 2014). Oleh karena itu, ada minat yang semakin besar pada teori implementasi untuk praktik industri. Banyak tantangan ada karena kompleksitas kasus tersebut dalam hal jumlah tahapan dan moda operasinya, jumlah produk dan sumber daya bersama biasanya bertemu dalam proses kehidupan nyata. Dalam karya ini Produksi ikan kalengan dipertimbangkan, yang terdiri dari beberapa batch dan kontinyu operasi produksi, sehingga bekerja dalam mode produksi semi kontinu. Banyak sekali studi yang membahas mode produksi batch atau kontinyu ditemukan dalam literature (Méndez et al., 2006).

Mempelajari proses produksi yoghurt reallife dan mengusulkan campuran waktu diskrit / kontinyu perwakilan. Masalahnya terutama difokuskan pada tahap pengemasan, karena itu diidentifikasi sebagai hambatan produksi. Tantangan utama dalam penjadwalan yang efisien industri proses makanan adalah pemodelan terintegrasi dari semua tahap produksi. Mengoptimalkan semua tahap pemrosesan meningkatkan kapasitas produksi pabrik dengan mengurangi waktu idle yang tidak perlu dan mengurangi biaya produksi produk akhir (Kopanos et al., 2010) 


\section{PEMBAHASAN}

Tabel 1. Data produksi Kue Semprong Bulan Januari - Desember 2018

\begin{tabular}{|l|c|c|}
\hline No & Bulan & $\begin{array}{c}\text { Kapasitas Produksi } \\
\text { (bungkus) }\end{array}$ \\
\hline 1 & Januari & 700 \\
\hline 2 & Februari & 850 \\
\hline 3 & Maret & 880 \\
\hline 4 & April & 890 \\
\hline 5 & Mei & 900 \\
\hline 6 & Juni & 1000 \\
\hline 7 & Juli & 750 \\
\hline 8 & Agustus & 780 \\
\hline 9 & September & 800 \\
\hline 10 & Oktober & 780 \\
\hline 11 & November & 900 \\
\hline 12 & Desember & 950 \\
\hline & Jumlah Produksi & 10180 \\
\hline & Rata-rata Produksi & 848,33 \\
\hline
\end{tabular}

Tabel 2. Rekapitulasi Jumlah Pegawai

\begin{tabular}{|r|c|c|}
\hline No & Jenis Pekerjaan & Jumlah Karyawan \\
\hline 1 & Pengelolahan Bahan & 4 \\
\hline 2 & Pencetakan & 5 \\
\hline 3 & Pengemasan & 5 \\
\hline & Jumlah Karyawan & 14 \\
\hline
\end{tabular}

Tabel 3. Perhitungan cycle time

\begin{tabular}{|r|c|c|c|c|c|c|c|c|c|c|}
\hline \multirow{2}{*}{ No } & \multirow{2}{*}{ Jenis Pekerjaan } & \multicolumn{6}{|c|}{ Hasil Pengukruan (dalam Menit) } & jumlah & $\sum\left(\mathrm{xi}^{2}\right)$ & \multirow{2}{*}{ Rata-rata } \\
\cline { 3 - 11 } & & 1 & 2 & 3 & 4 & 5 & 6 & $\sum(\mathrm{xi})$ & & \\
\hline 1 & Pengelolahan Bahan & 35 & 35 & 30 & 33 & 35 & 37 & 205 & 7033 & 34,2 \\
\hline 2 & Pencetakan & 5 & 7 & 8 & 5 & 5 & 7 & 37 & 237 & 6,2 \\
\hline 3 & Pengemasan & 10 & 11 & 11 & 13 & 10 & 12 & 67 & 755 & 11,2 \\
\hline
\end{tabular}


Perhitungan waktu baku pengelolahan bahan

\begin{tabular}{|c|c|c|c|}
\hline Subgrup & $\begin{array}{l}\text { Hasil Pengukuran } \\
\text { (menit) }\end{array}$ & $\begin{array}{l}\text { Nilai rata-rata } \\
\text { (menit) }\end{array}$ & $\operatorname{Range}_{\bar{R}}$ \\
\hline 1 & $35,35,30$ & 33,3 & 5 \\
\hline 2 & $33,35,37$ & 35 & 4 \\
\hline \multicolumn{2}{|r|}{ Jumlah } & $\begin{array}{l}\bar{X} \\
X\end{array}=34,2$ & $\bar{R}=4,5$ \\
\hline
\end{tabular}

Menentukan batas kontrol atas dan batas kontrol bawah

Batas Kontrol Atas

$$
\begin{aligned}
\overline{\mathrm{X}}+\mathrm{A}_{2} \overline{\mathrm{R}} & =34,2+(1,023 \mathrm{x} 4,5) \\
& =34,2+4,6053 \\
& =38,8053 \text { menit }
\end{aligned}
$$

Batas Kontrol Bawah

$$
\begin{array}{cc}
\overline{\mathrm{X}}-\mathrm{A}_{2} \overline{\mathrm{R}} \quad:-(1,0234 \times 4,5) \\
=34,2-4,6053 \\
=29,5947 \text { menit }
\end{array}
$$

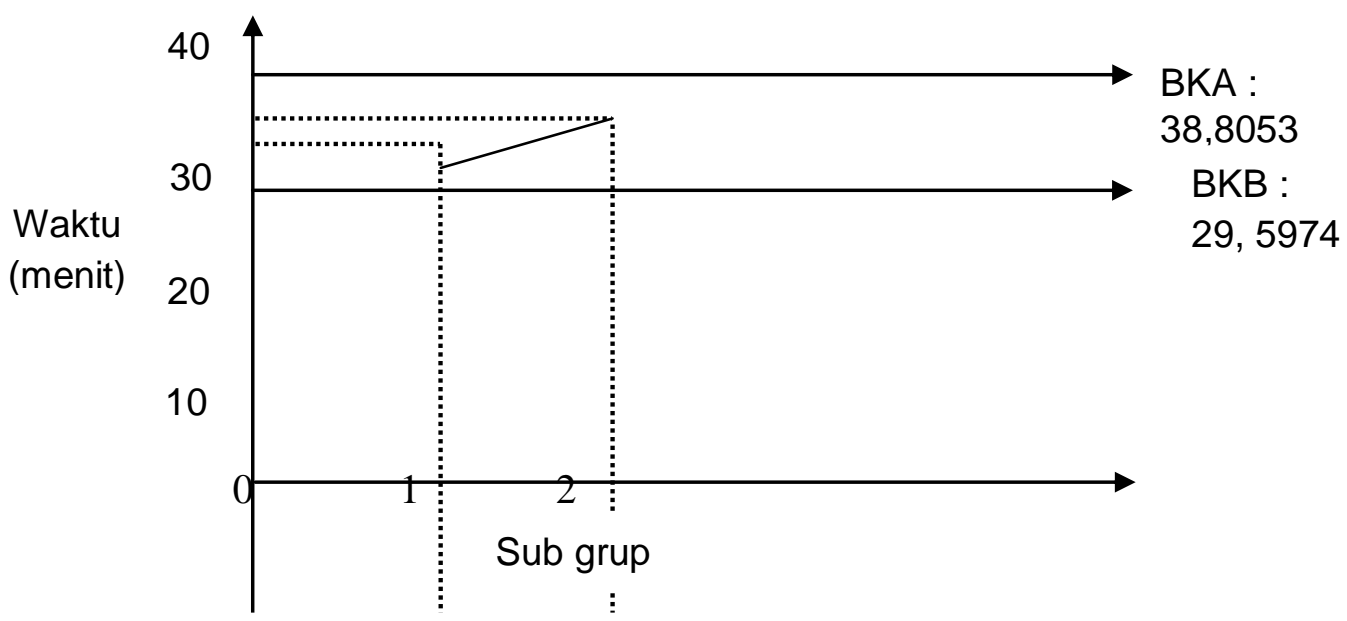

Gambar 1. Grafik Distribusi Hasil Pengukuran Pencampuran Bahan

Dari gratik di atas dapat dilihat bahwa semua rata-rata sub grup berada dalam batasbatas kontrol. Jadi, sub grup dari data pengukuran yang telah dilakukan seragam.

1. Melakukan tes kecukupan data

$$
\begin{aligned}
& N^{\prime}=\left[\frac{40 \sqrt{N \cdot\left(\sum \mathrm{xi}^{2}\right)-\left(\sum x i\right)^{2}}}{\sum x i}\right]^{2} \\
& N^{\prime}=\left[\frac{40 \sqrt{6 \cdot(7033)-(205)^{2}}}{205}\right]^{2}
\end{aligned}
$$




$$
\begin{aligned}
N^{\prime}=\left[\frac{40 \sqrt{42198-42025}}{205}\right]^{2} \\
=\left[\frac{40 \sqrt{173}}{205}\right]^{2} \\
=\left[\frac{40 \cdot 13,15}{205}\right]^{2} \\
=\left[\frac{526,11}{205}\right]^{2} \\
=[2,56]^{2} \\
=6,58
\end{aligned}
$$

Dari perhitungan tes kecukupan data dapat diketahui bahwa data yang dikumpulkan di lapangan pada tahapan pencampuran bahan sebaiknya dilakukan sebanyak 6,58 atau 7 kali pengukuran.

1) Waktu siklus

2) Waktu normal

$$
\begin{aligned}
W s & =\frac{\sum X i}{N} \\
& =\frac{205}{6}=34,2 \text { menit }
\end{aligned}
$$

$$
W n=W s \times P
$$

Di mana $\mathrm{P}$ adalah faktor penyesuaian dengan metode Westinghouse

$$
\begin{array}{cc}
\mathrm{P}=\text { Keterampilan dinilai good }\left(\mathrm{C}_{1}\right) & =+0,06 \\
\text { Usaha dinilai good }\left(\mathrm{C}_{1}\right) & =+0,05 \\
\text { Kondisi kerja dinilai fair }(\mathrm{E}) & =-0,03 \\
\text { Konsistensi dinilai poor }(\mathrm{F}) & =-0,04 \\
\text { Total } & =+0,04 \\
\text { Maka } \mathrm{P}=1+0,04 & \\
\quad=1,04 & \\
W n & =34,2 \times 1,04
\end{array}
$$$$
\text { Usaha dinilai good }\left(\mathrm{C}_{1}\right) \quad=+0,05
$$$$
\text { Konsistensi dinilai poor }(\mathrm{F}) \quad=-0,04
$$$$
=+0,04
$$

3) Waktu baku

$$
W b=W n+i(W n)
$$

Di mana i adalah faktor kelonggaran (Allowence)

Faktor kelonggaran (i)

1. Kebutuhan pribadi

$$
\begin{aligned}
& =2 \% \\
& =2 \%
\end{aligned}
$$

3. Fatique

1) Tenaga kerja yang kerja (duduk) =3\%

2) Tenaga yang dikeluarkan $\quad=1,5 \%$

3) Sikap kerja =0,5\%

4) Kelelahan mata $=2 \%$

5) Gerakan kerja $=0 \%$

6) Keadaan temperatur (normal) $=2 \%$ 
7) Keadaan atmosfer (ruang luas)

8) Keadaan lingkungan (baik, kebisingan) Total (i)

$$
\begin{aligned}
& W b=35,5+0,165(35,5) \\
& W b=35,5+5,85 \\
& W b=41,65 \text { menit }=0,69 \text { jam }
\end{aligned}
$$

\section{Menghitung Waktu Baku pada Tahap Pencetakan}

Menghitung harga rata-rata dari harga rata-rata sub grup

Tabel. Pengelompokkan Data dalam Sub Grup

Perhitungan waktu baku pengelolahan bahan

\begin{tabular}{|c|c|c|c|}
\hline Subgrup & $\begin{array}{c}\text { Hasil Pengukuran } \\
\text { (menit) }\end{array}$ & $\begin{array}{c}\text { Nilai rata-rata } \\
\text { (menit) }\end{array}$ & Range $_{\boldsymbol{R}}$ \\
\hline 1 & $5,7,8$ & 6,6 & 3 \\
\hline 2 & $5,5,7$ & 5,6 & 2 \\
\hline \multicolumn{2}{|c|}{ Jumlah } & $\bar{X}=6,1$ & $\overline{\boldsymbol{R}}=2,5$ \\
\hline
\end{tabular}

Menentukan batas kontrol atas dan batas kontrol bawah

Batas Kontrol Atas

$$
\begin{aligned}
\overline{\mathrm{X}}+\mathrm{A}_{2} \overline{\mathrm{R}} & =6,1+(1,0234 \times 2,5) \\
& =6,1+2,56 \\
& =8,66 \text { menit }
\end{aligned}
$$

Batas Kontrol Bawah

$$
\begin{aligned}
\overline{\bar{X}}-A_{2} \bar{R} \quad-(1,023 \times 2,5) \\
=6,1-2,56 \\
=3,54 \text { menit }
\end{aligned}
$$

1. Melakukan tes kecukupan data

$$
\begin{gathered}
N^{\prime}=\left[\frac{40 \sqrt{N \cdot\left(\sum \mathrm{xi}^{2}\right)-\left(\sum x i\right)^{2}}}{\sum x i}\right]^{2} \\
N^{\prime}=\left[\frac{40 \sqrt{6 \cdot(237)-(37)^{2}}}{37}\right]^{2} \\
N^{\prime}=\left[\frac{40 \sqrt{1422-1369}}{37}\right]^{2} \\
=\left[\frac{40 \sqrt{53}}{37}\right]^{2} \\
=\left[\frac{40.7,2}{37}\right]^{2} \\
=\left[\frac{291,2}{37}\right]^{2} \\
=[8,2]^{2} \\
=61,9
\end{gathered}
$$


Dari perhitungan tes kecukupan data dapat diketahui bahwa data yang dikumpulkan di lapangan pada tahapan pengovenan sebaiknya dilakukan sebanyak 61,9 atau 62 kali pengukuran.

1) Waktu siklus

2) Waktu normal

$$
\begin{aligned}
W s= & \frac{\sum X i}{N} \\
= & \frac{37}{6}=6,1 \text { menit }
\end{aligned}
$$

$$
W n=W s \times P
$$

Di mana $\mathrm{P}$ adalah faktor penyesuaian dengan metode Westing House

$\mathrm{P}=$ Keterampilan dinilai good $\left(\mathrm{C}_{1}\right) \quad=+0,06$

Usaha dinilai good $\left(\mathrm{C}_{1}\right) \quad=+0,05$

Kondisi kerja dinilai fair $(\mathrm{E}) \quad=-0,04$

$\begin{array}{ll}\text { Konsistensi dinilai fair }(\mathrm{F}) & =-0,02 \\ \text { Total } & =+0,05\end{array}$

Maka $\mathrm{P}=1+0,05$

$$
\begin{aligned}
& =1,05 \\
W n & =6,1 \times 1,05 \\
W n & =6,5 \text { menit }
\end{aligned}
$$

3) Waktu baku

$$
W b=W n+i(W n)
$$

Faktor kelonggaran (i)

1. Kebutuhan pribadi

2. Tak terhindarkan

3. Fatique

1) Tenaga kerja yang kerja (berdiri) $=2 \%$

2) Tenaga yang dikeluarkan $=3 \%$

3) Sikap kerja $=2 \%$

4) Kelelahan mata $=2 \%$

5) Gerakan kerja $=2,5 \%$

6) Keadaan temperatur (normal) $=3 \%$

7) Keadaan atmosfer (ruang luas) $=0,5 \%$

8) Keadaan lingkungan (baik, kebisingan) $\frac{=3 \%}{=22 \%}$
Total (i)

$W b=6,5+0,22(6,5)$

$W b=6,5+1,4$

$W b=7,9$ 
Menghitung Waktu Baku pada Tahap Pengemasan

Menghitung harga rata-rata dari harga rata-rata sub grup

\begin{tabular}{|c|c|c|c|}
\hline Subgrup & $\begin{array}{c}\text { Hasil Pengukuran } \\
\text { (menit) }\end{array}$ & $\begin{array}{c}\text { Nilai rata-rata } \\
\text { (menit) }\end{array}$ & Range $_{\boldsymbol{R}}$ \\
\hline 1 & $10,11,11$ & 10,6 & 1 \\
\hline 2 & $13,10,12$ & 11,6 & 3 \\
\hline & Jumlah & $\bar{X}=11,13$ & $\overline{\boldsymbol{R}}=2$ \\
\hline
\end{tabular}

Menentukan batas kontrol atas dan batas kontrol bawah Menentukan batas kontrol atas dan batas kontrol bawah

Batas Kontrol Atas

$$
\begin{aligned}
\overline{\overline{\mathrm{X}}+\mathrm{A}_{2} \overline{\mathrm{R}}} & =11,13+(1,023 \times 2) \\
& =11,13+2,046 \\
& =13,17 \text { menit }
\end{aligned}
$$

Batas Kontrol Bawah

$$
\begin{aligned}
\overline{\bar{X}}-A_{2} \bar{R} \quad 3-(1,023 \times 2) \\
=11,13-2,046 \\
=9,084 \text { menit }
\end{aligned}
$$

Melakukan tes kecukupan data

$$
\begin{gathered}
N^{\prime}=\left[\frac{40 \sqrt{N \cdot\left(\sum \mathrm{xi}^{2}\right)-\left(\sum x i\right)^{2}}}{\sum x i}\right]^{2} \\
N^{\prime}=\left[\frac{40 \sqrt{6 \cdot(755)-(67)^{2}}}{67}\right]^{2} \\
N^{\prime}=\left[\frac{40 \sqrt{4530-4489}}{67}\right]^{2} \\
=\left[\frac{40 \sqrt{41}}{37}\right]^{2} \\
=\left[\frac{40.6 .4}{67}\right]^{2} \\
=\left[\frac{256}{67}\right]^{2} \\
=[3,8]^{2} \\
=14,44
\end{gathered}
$$

Dari perhitungan tes kecukupan data dapat diketahui bahwa data yang dikumpulkan di lapangan pada tahapan pengemasan sebaiknya dilakukan sebanyak 14,44 atau 14 kali pengukuran. 
1) Waktu siklus

2) Waktu normal

$$
\begin{aligned}
W s & =\frac{\sum X i}{N} \\
& =\frac{67}{6}=11,17 \text { menit }
\end{aligned}
$$

$$
W n=W s \times P
$$

Di mana $\mathrm{P}$ adalah faktor penyesuaian dengan metode Westing House

$$
\begin{aligned}
& \mathrm{P}=\text { Keterampilan dinilai good }\left(\mathrm{C}_{1}\right) \quad=+0,06 \\
& \text { Usaha dinilai good }\left(\mathrm{C}_{2}\right) \quad=+0,02 \\
& \text { Kondisi kerja dinilai good }(\mathrm{C}) \quad=+0,02 \\
& \begin{array}{ll}
\text { Konsistensi dinilai fair }(\mathrm{E}) & =-0,02 \\
\text { Total } & =+0,08
\end{array} \\
& \text { Maka } \mathrm{P}=1+0,08 \\
& =1,08 \\
& W n=11,17 \times 1,08 \\
& W n=12,06 \text { menit }
\end{aligned}
$$

3) Waktu baku

Faktor kelonggaran (i)

1. Kebutuhan pribadi

$$
W b=W n+i(W n)
$$

2. Tak terhindarkan

3. Fatique
1) Tenaga kerja yang kerja (duduk)
2) Tenaga yang dikeluarkan
$=1 \%$
3) Sikap kerja
$=0,5 \%$
4) Kelelahan mata
$=0,5 \%$
5) Gerakan kerja
$=2 \%$
6) Keadaan temperatur (normal)
$=0,5 \%$
7) Keadaan atmosfer (ruang luas)
$=0,5 \%$
8) Keadaan lingkungan (baik, kebisingan)
Total (i)
$=0,5 \%$
$=1,5 \%$

$$
\begin{aligned}
& W b=12,06+0,11(12,06) \\
& W b=12,06+1,3 \\
& W b=13,36 \text { menit }=0,22 \text { jam }
\end{aligned}
$$

\section{Menghitung Jumlah Tenaga Kerja yang Dibutuhkan pada Masing-Masing Operasi}

Pada dasarnya, jumlah tenaga kerja yang dibutuhkan pada tiap operasi (satuan kerja) didasrkan atas waktu yang dibutuhkan untuk satu satuan produksi atau keluaran. Untuk menentukan output masing-masing, maka perhitungan dimulai dari operasi terakhir dan mundur ke operasi pertama (output pada operasi pengovenan merupakan 
input pada operasi pencetakan adonan, dan output pada operasi pencetakan adonan merupakan input pad pencampuran bahan).

1. Jumlah tenaga kerja yang dibutuhkan pada operasi pengelolaan bahan

Bila rata-rata hasil produksi IKM semprong selama Januari sampai Desember 2018 adalah 848,33 bungkus perhari dengan waktu tersedia 8 jam perhari, dan jam kerja yang digunakan adalah 1,74 jam, maka dibutuhkan output sebesar :

$$
\begin{aligned}
& \text { output }=\frac{\text { rata }- \text { rata produksi }}{\text { jam tersedia }} \\
& \text { output }=\frac{848,33 \text { bungkus }}{8 \text { jam }} \\
& =106 \text { bungkus /jam }
\end{aligned}
$$

Dengan demikian, maka input (produktivitas kerja) dapat dihitung sebagai berikut :

$$
\begin{aligned}
& \text { input }=\frac{\text { unit yang diproduksi (output) }}{\text { jam kerja yang digunakan }} \\
& \text { input }=\frac{106 \text { bungkus } / \mathrm{jam}}{0,69 \mathrm{jam}} \\
& =153,6 \text { bungkus } / j a m \\
& =154 \text { bungkus/jam }
\end{aligned}
$$

Jadi, jumlah tenaga kerja yang dibutuhkan pada operasi pengemasan adalah :

$$
\begin{aligned}
\sum \text { tenaga kerja } & =\frac{W b \times \text { input }}{E o} \\
& =\frac{0,69 \times 154}{4} \\
& =26 \text { orang }
\end{aligned}
$$

2. Jumlah tenaga kerja yang dibutuhkan pada operasi pencetakan

Seperti yang telah dijelaskan di atas, input pada operasi pengemasan merupakan output pada operasi pengovenan. Waktu kerja kerja yang digunakan adalah 0,13 jam sehingga input dapat dihiitung sebagai berikut :

$$
\begin{aligned}
\text { input } & =\frac{\text { output }}{\text { jam kerjayang digunakan }} \\
\text { input } & =\frac{106 \text { bungkus }}{0,13 \text { jam }} \\
& =815 \text { semprong } / \mathrm{jam}
\end{aligned}
$$

Jadi, jumlah tenaga kerja yang dibutuhkan pada operasi pengovenan sebagai berikut :

$$
\begin{aligned}
\sum \text { tenaga kerja } & =\frac{0,13 \times 815}{5} \\
& =21 \mathrm{orang}
\end{aligned}
$$


3. Jumlah tenaga kerja yang dibutuhkan pada operasi pengemasan

Untuk menghitung input pada operasi pencetakan adonan dengan waktu kerja yang digunakan 0,22 jam yaitu :

$$
\begin{array}{r}
\text { input }=\frac{\text { output }}{\text { jam kerja yang digunakan }} \\
=\frac{106 \text { bungkus }}{0,22 \text { jam }} \\
=482 \text { bungkus } / \mathrm{jam}
\end{array}
$$

Jadi, jumlah tenaga kerja yang dibutuhkan pada operasi pencetakan adonan yaitu :

$$
\begin{aligned}
\sum \text { tenaga kerja }= & \frac{482 \times 0,22}{4} \\
& =27 \mathrm{orang}
\end{aligned}
$$

\section{KESIMPULAN}

Dari hasil penelitian yang dilakukan pada IKM Usaha Aneka Semprong, maka dapat disimpulkan sebagai berikut :

1. Setelah melakukan perhitungan waktu siklus $\left(\mathrm{W}_{\mathrm{s}}\right)$ dan waktu normal $\left(\mathrm{W}_{\mathrm{n}}\right)$ tiap tahapan produksi, maka diperoleh waktu baku $\left(\mathrm{W}_{\mathrm{b}}\right)$ untuk masingmasing tahapan sebagai berikut :
1) Tahap I (pengelolaan Bahan) $=41,65$ menit $=0,69$ jam
2) Tahap II (pencetakan) $\quad=7,9 \quad$ menit $=0,12$ jam
3) Tahap III (pengemasan) = 13,36 menit $=0,22$ jam

2. Dari perhitungan output setiap tahapan produksi untuk satu jenis kue, diperoleh produktivitas kerja yang telah meningkat yaitu sebagai berikut :
a. Pengelolaan bahan : 154 bungkus
b. Pencetakan : 815 semprong
c. Pengemasan : 482 bungkus

3. Sedangkan dari hasil perhitungan jumlah tenaga kerja pada setiap tahapan produksi, tahapan produksinya harus 25 orang, sehingga membutukan pertambahan jumlah karyawan, mengingat permintaan yang semakin meningkat.

\section{DAFTAR PUSTAKA}

Kopanos, G. M., Méndez, C. A., \& Puigjaner, L. (2010). MIP-based decomposition strategies for large-scale scheduling problems in multiproduct multistage batch plants: A benchmark scheduling problem of the pharmaceutical industry. European journal of operational research, 207(2), 644-655. 
Lim, J. S., Foo, D. C., Ng, D. K., Aziz, R., \& Tan, R. R. (2014). Graphical tools for production planning in small medium industries (SMIs) based on pinch analysis. Journal of Manufacturing Systems, 33(4), 639-646.

Mei, Y., Ye, J., \& Zeng, Z. (2018). Two-way scheduling optimization of the supply chain in one-of-a-kind production based on dynamic production capacity restrictions. Journal of manufacturing systems, 47, 168-178.

Méndez, C. A., Cerdá, J., Grossmann, I. E., Harjunkoski, I., \& Fahl, M. (2006). Stateof-the-art review of optimization methods for short-term scheduling of batch processes. Computers \& chemical engineering, 30(6-7), 913-946.

Putri, K. S., Widyadana, I. G. A., \& Palit, H. C. (2015). Peningkatan Kapasitas Produksi pada PT. Adicitra Bhirawa. Jurnal Titra, 3(1), 69-76.

Rachman, T. (2013). Penggunaan Metode Work Sampling Untuk Menghitung Waktu Baku Dan Kapasitas Produksi Karungan Soap Chip Di PT SA. Jurnal Inovisi, 9(1), 48-60.

Risal, W. K., Puryani, P., \& Nursubiyantoro, E. (2017). PERENCANAAN KEBUTUHAN KAPASITAS PRODUKSI PADA SP ALUMINIUM. JURNAL OPSI-Optimasi Sistem Industri, 10(1), 11-18.

Salnikov, V., Galimov, D., Mikheeva, O., Gnidchenko, A., \& Rybalka, A. (2017). Russian manufacturing production capacity: Primary trends and structural characteristics. Russian Journal of Economics, 3(3), 240-262

Ushada, M., Okayama, T., \& Murase, H. (2015). Development of Kansei Engineering-based watchdog model to assess worker capacity in Indonesian small-medium food industry. Engineering in agriculture, environment and food, 8(4), 241-250. 